\title{
DIVERTICULA OF THE JEJUNUM
}

\author{
WALLACE I. TERRY, M.D., AND FREDERICK R. MUGLER, M.D. \\ SAN FRANCISCO
}

This case is reported because of the rarity of diverticula of the jejunum.

\section{REPCRT OF CASE}

A woman, aged 59 years, complained of symptoms typical of duodenal ulcer, which had been present for only a few months and were gradually increasing in intensity. She had been constipated for years. She was of medium stature, well nourished, but not obese. Her weight had remained constant for several years. She had had the ordinary diseases of childhood and had borne three children. Fifteen years before the present complaint, while living in one of the Southern states, she had had amebic dysentery and had been treated in a hospital for six weeks with apparent cure. The clinical diagnosis of duodenal ulcer was confirmed by roentgenogram and later at operation. These roentgenograms have since been carefully studied, but they show no evidence of jejunal diverticula.

At the operation, Jan. 24, 1917, in picking up the jejunum, preparatory to performing a posterior gastrojejunostomy, five diverticula of the jejunum were discovered. Two of these were about $2 \mathrm{~cm}$. long by $1.5 \mathrm{~cm}$. wide, and the other three were smaller. All were ovoid in shape. They were from 8 to $16 \mathrm{~cm}$. apart, beginning about $15 \mathrm{~cm}$. below the duodenojejunal flexure, and all were on the concave side of the jejunum, but not between the layers of mesentery. There seemed to be a definite relation between the blood vessels and the diverticula in that the larger diverticula had rather large blood vessels running over them and the smaller ones looked as if the blood vessels pierced their apexes. There was a fine weblike film of adhesions between the convex surface of the jejunum at its upper part and the gastrocolic omentum, but these adhesions were not connected with the diverticula. The two larger diverticula were inverted into the lumen of the intestine, using fine iodized catgut, and the smaller ones were left undisturbed. A posterior gastrojejunostomy was then performed, employing a portion of the jejunum above the diverticula.

Recovery from the operation was prompt, and the patient returned to her home in Oregon. She remained perfectly well until August, 1918, more than a year and a half after the operation, when she developed an acute intestinal obstruction, which necessitated an operation. Dr. Warren Hunt of Klamath Falls, Ore., has kindly written us that he found this condition:

"The bowel obstruction was caused by an irregular enterolith filling the lumen of the upper portion of the jejunum. This was broken up without opening the bowel, and subsequently passed, resembling yellow shale. The mass formed in one of the diverticula discovered in the first operation." The patient has since remained well.

\section{REPORTS OF THE CONDITION IN THE LITERATURE}

A rather careful search of the literature has revealed but nineteen cases of jejunal diverticula. It is, however, possible that in some of 


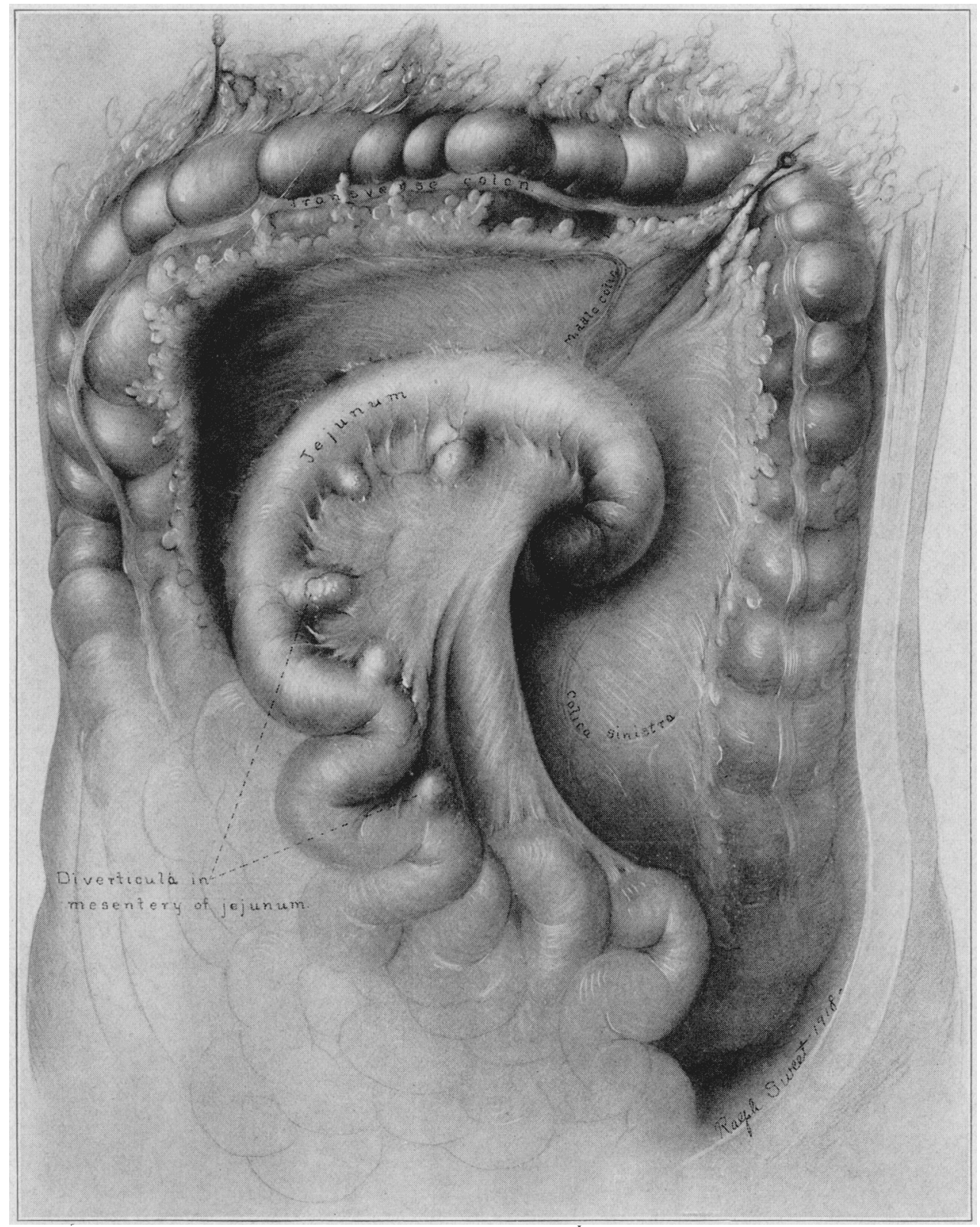

Diverticula of the jejumum, discovered at operation, in the authors' case. 
the cases reported as diverticula of the small intestine, the jejunum was involved, but when nothing definite has been stated they have not been included in our list.

That diverticula may occur in any part of the intestinal tract is a well established fact. Their frequency is greatest in the colon; they are less frequent in the ileum and duodenum, and least frequent in the jejunum and rectum. The etiology is not well understood. Cachexia, constipation, senility, obesity, a primary state of adiposity and subsequent wasting, pressure from within, traction from without, weak places at the mesenteric border, due to penetration by the large vessels, muscular deficiency of the intestinal wall and many others have been mentioned as etiologic factors contributing to the formation of these diverticula.

\section{CLASSIFICATION OF DIVERTICULA}

Diverticula are classified as congenital and acquired, true and false. In true diverticula, all of the intestinal coats are present, whereas the false type are hernial protrusions of the mucosa through the muscularis, carrying the serosa as a covering. The congenital diverticula are usually true and the acquired are usually false diverticula, but exceptions to this rule have been found. It seems probable that a congenital true diverticulum, if subjected to long continued distention, would increase in size, the muscularis would atrophy and rupture, and thus it would be converted into a false diverticulum. Meckel's is the most common congenital diverticulum. It is usually on the convex surface of the lower ileum, whereas the majority of other diverticula appear near the mesenteric border or between the layers of mesentery. The most probable explanation for the occurrence of acquired diverticula on the concave surface of the intestine is the weakening of the walls by the penetration of the blood vessels at the mesenteric border.

That the jejunum is less subject to diverticula than the ileum is probably due to three factors: the fluid content of the jejunum, its thicker wall and its larger lumen.

CASES OF JEJUNAL DIVERTICULA REPORTED IN THE LITERATURE

The appended cases of jejunal diverticula are those that we have been able to find in the literature:

Sir Astley Cooper, ${ }^{1}$ in 1844 , reported a case of multiple diverticula of the jejunum, situated between the layers of mesentery and varying in size from a pea to a walnut. They were found postmortem in a man, aged about 50, who died of general dropsy.

1. Cooper, Astley: The Anatomy and Surgical Treatment of Abdominal Hernia, Philądelphia, 1844, p. 364. 
Cornillon, ${ }^{2}$ in 1869 , reported a case of a single diverticulum, the size of a hen's egg, found near the middle of the jejunum. It was discovered, at necropsy, in a woman, aged 30 , who died following placenta praevia. No further details are given.

Osler, ${ }^{3}$ in 1881, reported the case of a man, aged 65 , who died of an acute enteric attack with melena. He had suffered for years with rumbling noises in the abdomen, particularly after eating. Necropsy disclosed fifty-three diverticula in the jejunum on the mesenteric border. "They ranged in size from a cherry to a large apple." They were not connected with the enteric trouble which caused death.

Moore, ${ }^{4}$ in 1883 , described a specimen, obtained at necropsy, of jejunum in which there were three diverticula and also a congenital stricture at the commencement of the jejunum. The diverticula were 1 inch in diameter and were situated on the mesenteric side. The walls consisted of all the intestinal coats and were not mere hernial protrusions. There had been no symptoms produced by these diverticula. The specimen was obtained from a man, aged 40 , who died of bronchitis.

Buzzi, $^{5}$ in 1885 , reported a single diverticulum 1 meter from the upper end of the jejunum on the mesenteric side. It measured 23 by $32 \mathrm{~mm}$. and had all the intestinal coats. It was found, at necropsy, in a man, aged 77 , who died following perforative peritonitis from pyloric carcinoma. Buzzi considered this a misplaced Meckel's diverticulum.

Buchwald and Janicke, ${ }^{6}$ in 1887 , reported a case found at operation in a boy, aged 6, with obstruction of the bowels due to a cystic tumor of the jejunum. After resection of the bowel, it was found that the lining of the cyst was continuous with the mucous membrane of the jejunum by a narrow slit which was sealed. The opening was on the mesenteric side.

Virchow, ${ }^{7}$ in 1890 , reported a necropsy specimen of multiple diverticula of the jejunum and also some in the ileum. The jejunal diverticula were the size of an egg and all were on the mesenteric side

2. Cornillon: Diverticulum de l'intestin grêle, Bull. Soc. anat. de Par. 44: $525,1869$.

3. Osler, William: Notes on Intestinal Diverticula, Ann. Anat. and Surg. 4:202-207, 1881.

4. Moore, N.: Diverticula of the Small Intestine, Brit. M. J. 2:920, 1883. Tr. Brit. Path. Soc. 25:202, 1884.

5. Buzzi: Ueber einen Fall von angebornem Divertikel des Jejunums, Arch. f. path. Anat. 100:357, 1885.

6. Buchwald, A., and Janicke. O.: Ueber Darmcysten (Enterokystome) als Ursache eines completen Darmverschlusses, Deutsch. med. Wchnschr. 23: 868, 1887.

7. Virchow, Rudolf: Verhandl. d. Berl. med. Gesellsch., 1890, p. 116. 
with rather large opening into the bowel. All were hernias through the muscularis. The body was that of a lean, old man.

Edel, ${ }^{8}$ in 1894, reported a necropsy specimen of seven diverticula of the jejunum varying in size from a walnut to an apple. All were located on the mesenteric side and followed the course of the blood vessels. Other diverticula were present in the colon. The woman was 73 years of age.

Seippel, ${ }^{9}$ in 1895 , reported a case of multiple jejunal sacculations.

Hansemann, ${ }^{10}$ in 1896, reported a necropsy specimen from a boy, aged 14. There was a single diverticulum in the jejunum on the convex surface of the bowel and to its apex was attached an accessory pancreas. He also reported the case of a man, aged 85, who died of pneumonia. There were 400 small diverticula in the small intestine, most of them in the jejunum. All were located near the mesenteric attachment and at those places where blood vessels penetrated th: muscularis.

Grassberger, ${ }^{11}$ in 1897 , reported a necropsy specimen from a man, aged 73. There was a diverticulum in the stomach, two in the duodenum, many in the colon, and many pea sized and thirteen walnut sized diverticula in the upper jejunum. All were on the mesenteric side of the bowel and were without muscularis. The cause of death was a perforating ulcer of the duodenum.

Nicholls, ${ }^{12}$ in 1899 , reported a necropsy specimen from a woman, aged 64. There were fifty diverticula in the jejunum varying in size from a dried pea to a walnut. All were at the mesenteric attachment and were hernias through the muscularis. The woman had had double inguinal hernia for thirty years and chronic bronchitis for twenty-five years. She was of spare build.

Fischer ${ }^{13}$ reported, in 1900 , a museum specimen of a piece of jejunum containing a diverticulum, the size of a bean and within the layers of the mesentery. It communicated by a small opening with the bowel. The muscularis was absent.

8. Edel, M.: Ueber erworbene Darmdivertikel, Arch. f. path. Anat. 138: $347,1894$.

9. Seippel: Ueber erworbene Darmdivertikel, Diss., Zurich, 1895.

10. Hansemann, D.: Ueber die Entstehung falscher Darmdivertikel, Arch. f. path. Anat. 164:400, 1896.

11. Grassberger, R.: Ein Fall von multipler Divertikelbildung des Darmtractes, complicirt mit peptischem Geschwür am Pylorus, Wien. klin. Wchnschr. 10: 149-151, 1897.

12. Nicholls, A. G.: Path. Spec. Multiple Diverticula of the Small Intestine, Philadelphia M. J. 3:700-701, 1899.

13. Fischer, M. H.: False Diverticula of the Intestine, J. Exper. M. 5:333, 1900. 
Taylor and Lakin, ${ }^{14}$ in 1910, reported a necropsy specimen from a woman, aged 68 , who died of pneumonia. There were large numbers of diverticula in the upper jejunum varing in size from a pea to an unshelled walnut. They projected between the layers of mesentery and all had well defined mouths into the bowel. There were also numerous pouches in the colon.

Latarjet and Murard, ${ }^{15}$ in 1914, reported a necropsy specimen from a woman, aged 50 . There was a single diverticulum in the jejunum, $23 \mathrm{~cm}$. below the opening of the common duct. It was 2.5 by $5 \mathrm{~cm}$. in size and communicated with the bowel by a large opening. It was on the mesenteric border and in the course of the blood vessels.

Braithwaite ${ }^{16}$ reported, in 1918, a necropsy specimen from a man, aged 45. There were two diverticula in the second part of the duodenum, two or three in the first part of the jejunum and about sixty in the next yard of jejunum. All were situated along the mesenteric attachment. The largest had a capacity of 25 c.c.

Case ${ }^{17}$ reported, in 1920 , multiple jejunal diverticula in a man, aged 61, who complained of "indigestion." Roentgen-ray examination showed a diverticulum located apparently a few centimeters below the duodenojejunal junction. At operation, about a dozen diverticula were found in the upper jejunum-one was $5 \mathrm{~cm}$. in diameter. They were between the folds of mesentery. The patient recovered after a resection of the involved area. Case ${ }^{17}$ also reports the case of a man, aged 73 , in whom twenty-five or thirty sacculations in the jejunum and upper ileum were diagnosed by roentgen-ray examination. The diagnosis was later confirmed by operation. There were also multiple diverticula in the pelvic colon.

Terry and Mugler in the case here reported of a woman, aged 59, found five diverticula of the upper jejunum at an operation for duodenal ulcer. All were located on the mesenteric side; two of them were treated by inversion. A later operation was performed for obstruction due to enterolith forming in a diverticulum.

COMMENT

Analysis of these twenty cases demonstrates these facts: There were twelve males and six females (sex was not given in two cases). The ages varied from 6 to 85 years--only three patients were less than

14. Taylor and Lakin: Perforative Peritonitis Originating in Pouches of the Large Intestine. Lancet 1:495, 1910.

15. Latarjet, A., and Murard, J.: Les diverticules de l'intestin grêle, Lyon chir. 40:425, 1914.

16. Braithwaite, V.: A Case of Diverticulitis of the Sinall Intestine, Guy's Hosp. Gaz. 32:77, 1918.

17. Case, J. T.: Diverticula of Small Intestine, Other Than Meckel's Diverticulum, J. A. M. A. 75:1463 (Nov. 27) 1920. 
40 and fifteen were more than 40 (age not stated in two cases). The diverticula were single in six cases, multiple in fourteen. In one case, a single diverticulum was present on the side of the jejunum opposite the mesentery, and this was thought to be due to traction from an accessory pancreas. In sixteen cases, the diverticula were on the mesenteric side (location was not stated in three cases).

It is interesting to note that only three patients presented symptoms due to the diverticula. The two cases reported by Case are of great interest, inasmuch as a correct preoperative diagnosis was made in both. In fifteen cases the diagnosis was made at necropsy.

240 Stockton Street. 